\title{
Csnkle Is a Genetic Regulator of Sensitivity to Psychostimulants and Opioids
}

\author{
Camron D Bryant', Clarissa C Parker', Lili Zhou ${ }^{2,3}$, Christopher Olker, ${ }^{2,3}$, Ramalakshmi Y Chandrasekaran ${ }^{4}$, \\ Travis T Wager ${ }^{4}$, Valerie J Bolivar ${ }^{5,6}$, Andrew S Loudon ${ }^{7}$, Martha H Vitaterna ${ }^{2,3}$, Fred W Turek ${ }^{2,3}$ and \\ Abraham A Palmer*, I,8 \\ 'Department of Human Genetics, University of Chicago, Chicago, IL, USA; ${ }^{2}$ Center for Sleep and Circadian Biology, Northwestern University, \\ Evanston, IL, USA; ${ }^{3}$ Department of Neurobiology and Physiology, Northwestern University, Evanston, IL, USA; ${ }^{4}$ Neuroscience Medicinal Chemistry, \\ Pfizer Worldwide Research Development, Groton, CT, USA; ${ }^{5}$ Wadsworth Center, New York State Department of Health, Albany, NY, USA; \\ ${ }^{6}$ Department of Biomedical Sciences, School of Public Health, State University of New York at Albany, Albany, NY, USA; ${ }^{7}$ Faculty of Life Sciences, \\ University of Manchester, Manchester, UK; ${ }^{8}$ Department of Psychiatry and Behavioral Neuroscience, University of Chicago, Chicago, IL, USA
}

Csnkle, the gene encoding casein kinase I-epsilon, has been implicated in sensitivity to amphetamines. Additionally, a polymorphism in CSNKIE was associated with heroin addiction, suggesting that this gene may also affect opioid sensitivity. In this study, we first conducted genome-wide quantitative trait locus (QTL) mapping of methamphetamine (MA)-induced locomotor activity in C57BL/6J (B6) $\times$ DBA/ 2] (D2)- $F_{2}$ mice and a more highly recombinant $F_{8}$ advanced intercross line. We identified a QTL on chromosome I5 that contained Csnkle (63-86 Mb; Csnkle =79.25 Mb). We replicated this result and further narrowed the locus using B6.D2 ${ }^{\text {Csnkle }}$ and D2.B6 ${ }^{\text {Csnkle }}$ reciprocal congenic lines (78-86.8 and 78.7-81.6 Mb, respectively). This locus also affected sensitivity to the $\mu$-opioid receptor agonist fentanyl. Next, we directly tested the hypothesis that Csnkle is a genetic regulator of sensitivity to psychostimulants and opioids. Mice harboring a null allele of Csnkle showed an increase in locomotor activity following MA administration. Consistent with this result, coadministration of a selective pharmacological inhibitor of Csnkle (PF-4800567) increased the locomotor stimulant response to both MA and fentanyl. These results show that a narrow genetic locus that contains Csnk le is associated with differences in sensitivity to MA and fentanyl. Furthermore, gene knockout and selective pharmacological inhibition of Csnk le define its role as a negative regulator of sensitivity to psychostimulants and opioids.

Neuropsychopharmacology (2012) 37, 1026-1035; doi:I0.1038/npp.20 I 1.287; published online 16 November 20I I

Keywords: QTL; CK-I; psychomotor; dopamine; DARPP-32; opiate

\section{INTRODUCTION}

Psychostimulants and opioids increase locomotor activity in rodents in part via dopamine release in the nucleus accumbens (Di Chiara and Imperato, 1988; Wise and Bozarth, 1987), an important brain area for reward learning (Flagel et al, 2011). Variation in sensitivity to the locomotor stimulant effect of amphetamines and opioids is heritable (Belknap et al, 1998; Phillips et al, 2008; Gill and Boyle, 2008; Oliverio et al, 1975; Philip et al, 2010). Because epidemiological studies indicate that sensitivity to drug liking in humans can predict an individual's susceptibility to drug abuse (Haertzen et al, 1983; Schuckit, 2009), drug

* Correspondence: Professor AA Palmer, Department of Human Genetics, University of Chicago, 920 E 58th Street, CLSC 507D, Chicago, IL 60637 , USA, Tel: + I 773834 2897, Fax: + I 773834 0505,

E-mail: aap@uchicago.edu

Received I September 201 I; revised 14 October 201 I; accepted 17 October 2011 sensitivity and abuse are hypothesized to share a genetic basis. This hypothesis is supported by genetic association studies in humans that have identified genes that influence both acute sensitivity (Hamidovic et al, 2009, 2010; Lott et al, 2005, 2006; Dlugos et al, 2011) and dependence (Ho et al, 2010).

We previously identified a quantitative trait locus (QTL) for methamphetamine (MA) sensitivity on chromosome 15 near Csnkle (Palmer et al, 2005), the gene encoding casein kinase 1-epsilon. Csnkle is a member of the casein kinase-1 (CK-1) family of serine/threonine kinases (Cheong and Virshup, 2010). CK-1 phosphorylates dopamine- and cyclic adenosine monophosphate-regulated neuronal phosphoprotein-32 (DARPP-32) (Greengard, 2001), which regulates psychostimulant- and opioid-induced locomotor activity (Borgkvist and Fisone, 2007; Borgkvist et al, 2007). CK-1 also phosphorylates per proteins (Meng et al, 2008) that regulate gene transcription in circadian rhythms and the molecular and behavioral adaptations to psychostimulants (Falcon and McClung, 2008). Last, CK-1 phosphorylates 
various proteins of the canonical Wnt signaling pathway and may contribute to neuropsychiatric conditions such as mood disorders (Li and Jope, 2010).

We previously showed that the CSNK1E SNP rs135745 was associated with amphetamine-induced subjective euphoria in healthy human volunteers (Veenstra-VanderWeele et al, 2006) and have since replicated this finding in a new cohort of 282 subjects (Amy et al, unpublished data). Additionally, the CSNK1E SNP rs1534891 was associated with heroin addiction (Levran et al, 2008). Furthermore, coadministration of the casein kinase 1- $\delta$ (Csnk1d)-preferring inhibitor PF-670462 with MA decreased locomotor activity and DARPP-32 phosphorylation in mice (Bryant et al, 2009b), and a similar result was observed following coadministration of PF-670462 with amphetamine in rats (Li et al, 2011). Conversely, Csnk1d overexpression in the forebrain resulted in baseline hyperactivity and an increased locomotor response to amphetamine (Zhou et al, 2010). Together, these results suggest that both Csnkle and Csnk1d are important for sensitivity to drugs of abuse. However, because PF-670462 only exhibits six-fold selectivity for Csnk1d over Csnk1e (Walton et al, 2009; Meng et al, 2010), it is unclear if our previous results were mediated by Csnk1d or Csnk1e (Bryant et al, 2009b; Li et al, 2011).

In this study, we employed a forward genetic approach using $\mathrm{F}_{2}$ and $\mathrm{F}_{8}$ advanced intercross mice as well as reciprocal congenic lines derived from the $\mathrm{C} 57 \mathrm{BL} / 6 \mathrm{~J}$ (B6) and DBA/2 J (D2) strains to fine map a QTL that influences MA sensitivity (Palmer et al, 2005). Because we previously observed a higher D2 allelic frequency at the Csnk1e locus in a mouse line selected for high MA sensitivity (Palmer et al, 2005), we hypothesized that the D2 allele would increase drug sensitivity. Based on the location of our QTL and prior studies implicating Csnkle in the response to drugs of abuse, we further hypothesized that Csnkle regulates sensitivity to psychostimulants and opioids. Thus, we examined the effect of a Csnkle-null mutation or pharmacological inhibition with the new selective Csnkle inhibitor PF-4800567 (Walton et al, 2009; Meng et al, 2010) on the locomotor response to MA and the $\mu$-opioid receptor agonist fentanyl.

\section{MATERIALS AND METHODS}

\section{Environment and Housing}

All experiments were performed in accordance with the NIH Guidelines for the Care and Use of Laboratory Animals and were approved by IACUC at the University of Chicago and Northwestern University. Mouse colony rooms were maintained on a 12/12 light/dark cycle with lights on at $0600 \mathrm{~h}$. Two to five same-sex littermates were housed in clear plastic shoe box-sized cages. Mice were allowed ad libitum access to food and water, except during testing. An approximately equal number of female and male mice were employed for each genotype/treatment group for each study.

\section{B6 $\times$ D2- $F_{2}$ and $-F_{8}$ Advanced Intercross Mice}

Inbred female B6 and male D2 mice were obtained from The Jackson Laboratory (JAX; Bar Harbor, ME). These mice were used to produce $\mathrm{B} 6 \times \mathrm{D} 2 \mathrm{~F}_{1}$ mice, which were then intercrossed to create the $\mathrm{F}_{2}(N=676)$ and $\mathrm{F}_{8}(N=552)$ generations. $\mathrm{F}_{8}$ breeding was pseudorandom to ensure that siblings and close relatives were not mated with one another. Additionally, breeding pairs were rotated after each litter to avoid producing large numbers of full sibs. However, the $\mathrm{F}_{8}$ generation inevitably contained many sibs, half-sibs, and cousins as well as more distant and complex relationships that were accounted for in the analysis. $F_{2}$ and $\mathrm{F}_{8}$ mice were 7-13 weeks old at the time of testing.

For genotyping, DNA from the $\mathrm{F}_{2}$ generation was extracted and genotyped by KBiosciences (Hoddesdon, Hertfordshire, UK) using KASPar, a fluorescence-based PCR assay. Markers consisted of 164 evenly spaced, informative SNPs that were selected from a previous study (Petkov et al, 2004). In the $\mathrm{F}_{8}$ generation, DNA was extracted and then genotyped using the Illumina Mouse Medium Density Linkage Panel (Illumina, San Diego, CA) at the Genomics Core Facility at Northwestern University (http://web.cgm.northwestern.edu/cgm/Core-Facilities/ Genomics-Core). The SNP array consisted of 1449 loci. Of these, 909 were polymorphic between B6 and D2 mice and 882 of these markers were used in this study.

\section{B6.D2 ${ }^{\text {Csnk1e }}$ and D2.B6 ${ }^{\text {Csnk1e }}$ Reciprocal Congenic Mice}

$\mathrm{B} 6 . \mathrm{D} 2^{\text {Csnkle }}$ mice were derived from a larger congenic line that was previously backcrossed to B6 (JAX) for more than 10 generations (Iakoubova et al, 2001). D2.B6 ${ }^{\text {Csnkle }}$ mice were derived from a larger congenic line at the Wadsworth Center (Albany, NY) that was previously backcrossed to D2 (JAX) for more than 10 generations. We further backcrossed both congenic lines to their respective background strains until we obtained smaller congenic regions capturing the Csnkle locus and then intercrossed (heterozygous-heterozygous breeding) to yield congenics and wildtype littermates for simultaneous phenotyping. Because the inhibitor study required a large number of mice, we used homozygous-homozygous breeders chosen from the offspring of heterozygous-heterozygous breeders and from a single generation of inbreeding. Congenic mice were 7-12 weeks old at the time of testing.

For genotyping, we first used a series of TaqMan SNP markers on chromosome 15 from Applied Biosystems (Foster City, CA) to monitor recombination events. In order to precisely determine the congenic boundaries, we then genotyped SNPs chosen from the Mouse Phenome Database (http://phenome.jax.org/) using PCR amplification, gel extraction, and DNA Sanger sequencing at the University of Chicago core facility (http://cancer-seqbase. uchicago.edu/). We then re-genotyped two mice from each line on the same SNP array as described above to reveal any regions of residual heterozygosity $(\mathrm{RH})$. $\mathrm{RH}$ SNPs were confirmed via DNA sequencing from the same individuals.

\section{Csnkle Knockout Mice}

Csnkle knockout mice were generated as previously described (Meng et al, 2008). Csnkle knockout mice were backcrossed for six generations to C57BL/6N mice. Heterozygous-heterozygous breeding was used to generate the first cohort of mice for testing (27 offspring) followed by 
homozygous-homozygous breeding of a single generation of breeders for the second cohort of mice (27 offspring), equaling a total of 54 mice (26 Csnkle wild types and 28 Csnkle knockouts). Mice were 8-21 weeks old at the time of testing. Approximately equal numbers of age-matched wild types and knockouts were always tested within the same experimental session. Genotyping was conducted via PCR and gel electrophoresis and SYBR green staining using primers (5'-CGGGAAAACAAGAACCTGAC- $3^{\prime}$ ) and (5'-TAGGTCATCTCGACGGCTTT- $\left.3^{\prime}\right)$ to generate a $750 \mathrm{bp}$ band for the wild-type allele and using primers (5'-CGGCTC AGTGATGGGTACT- $3^{\prime}$ ) and (5'-TAGGTCATCTCGACGGCT TT $-3^{\prime}$ ) to generate a $730 \mathrm{bp}$ band for the null allele.

\section{Drugs}

Methamphetamine $\mathrm{HCl}$ (MA; Sigma-Aldrich, St Louis, MO; $2 \mathrm{mg} / \mathrm{kg}$, i.p.) and fentanyl citrate (Sigma-Aldrich; $0.2 \mathrm{mg} / \mathrm{kg}$, i.p.) were dissolved in $0.9 \% \mathrm{NaCl}$. The dose of MA was chosen based on our prior QTL mapping and pharmacological studies (Palmer et al, 2005; Bryant et al, 2009b). The dose of fentanyl was chosen based on our previous studies employing this dose in B6 mice in the open field (Bryant et al, 2009a, 2009c). PF-4800567 (PF; $40 \mathrm{mg} / \mathrm{kg}$, i.p.) was dissolved in a $10 \% \mathrm{v}-\mathrm{v}$ solution of 1,2-propanediol (polypropylene glycol)/double deionized water containing $30 \%(\mathrm{w}-\mathrm{v})$ sulfobutylether- $\beta$-cyclodextrin (Captisol (CyDex Pharmaceuticals, Lenexa, KS)). The polypropylene glycol/PF solution was briefly sonicated using a Qsonica Misonix S-4000 (Farmingdale, NY) before adding $30 \%$ Captisol solution. The dose of PF was chosen based on previously published studies in mice (Walton et al, 2009; Meng et al, 2010), a limit in solubility at higher concentrations, and pilot studies indicating its effectiveness at modulating drug-induced locomotor activity. PF has been shown to exhibit 20-fold greater selectivity for Csnk1e vs Csnk1d and has been useful in clarifying the importance of the two isoforms in regulating circadian rhythms (Walton et al, 2009; Meng et al, 2010).

\section{Locomotor Testing Procedure}

Testing was conducted between $0800 \mathrm{~h}$ and $1600 \mathrm{~h}$. Mice were transported from the adjacent vivarium into the test room and were allowed to habituate for at least $30 \mathrm{~min}$ before testing. Just before testing, mice were removed from their home cages and placed in clean holding cages for $\sim 5 \mathrm{~min}$ and then received an intraperitoneal (i.p.) injection of saline $(10 \mathrm{ml} / \mathrm{kg})$ on days 1 and 2 and either MA $(2 \mathrm{mg} / \mathrm{kg}$, i.p) or saline (i.p.) or fentanyl $(0.2 \mathrm{mg} / \mathrm{kg}$, i.p.) on day 3 . Mice were then immediately placed in the center of the open field and that total distance traveled was recorded in 5-min bins over $30 \mathrm{~min}$. Locomotor activity was measured using the automated Versamax activity chambers (AccuScan, Columbus, $\mathrm{OH} ; \mathrm{F}_{2}, \mathrm{~F}_{8}$, and congenic mice at University of Chicago) or Big Brother software (Coulbourn Instruments, Whitehall, PA; Csnkle knockout and wild-type mice at Northwestern University). The open field was $37.5 \times 37.5 \times$ $35.7 \mathrm{~cm}$ in size. For Versamax, beam breaks were recorded on a computer and converted into total distance traveled $(\mathrm{cm})$. For Big Brother, the dimensions of the image width of the open field were used to convert locomotor activity into total distance traveled $(\mathrm{cm})$ that was recorded on a computer.

\section{Inhibitor Study}

When comparing the vehicle solution $v s$ saline in pilot studies, there was a progressive decrease in locomotor activity following two vehicle exposures on days 1 and 2 . This could be caused both by a larger injection volume and by the fact that one of the components of the vehicle solution, polypropylene glycol, has been shown to decrease locomotor activity at high concentrations (Singh et al, 1982). We controlled for potential effects of vehicle across treatment groups by including both components of the vehicle (polypropylene glycol plus Captisol) in the control solution that did not contain PF. Additionally, to limit the amount of vehicle exposure, we chose to administer saline during habituation on days 1 and 2 and to only administer the vehicle solution on day 3 (containing PF or vehicle alone). On day 3 , mice were injected with either vehicle $(20 \mathrm{ml} / \mathrm{kg}$, i.p., left cavity) or PF $(40 \mathrm{mg} / \mathrm{kg}$, i.p., $20 \mathrm{ml} / \mathrm{kg}$, left cavity) followed immediately thereafter with saline ( $10 \mathrm{ml} / \mathrm{kg}$, i.p.; right cavity), MA ( $2 \mathrm{mg} / \mathrm{kg}$, i.p., $10 \mathrm{ml} / \mathrm{kg}$, right cavity), or fentanyl $(0.2 \mathrm{mg} / \mathrm{kg}$, i.p., $10 \mathrm{ml} / \mathrm{kg}$, right cavity). Mice were then placed into the open field and the total distance traveled was recorded over $30 \mathrm{~min}$.

\section{QTL Analysis}

For QTL analysis, kinship coefficients and identity coefficients were calculated using the pedigree for the AIL, which began in the $F_{1}$ and continued to the $F_{8}$ generation as previously described (Cheng et al, 2010; Parker et al, 2011). Genome-wide association analysis was performed in the combined population of the $\mathrm{F}_{2}$ and $\mathrm{F}_{8}$ intercrosses using the $\mathrm{R}$ package QTLRel (Cheng et al, 2011). This software accounts for the complex relationships (eg, sibling, halfsibling, cousins) among $\mathrm{F}_{8}$ mice by using a mixed model. In addition, genetic models where sex was included as an additive or interactive covariate were explored; however, these models did not affect the results and thus the sexes were combined for the final analysis. For each analysis, $P<0.05$ significance thresholds were determined via permutation analysis (1000 permutations).

\section{Behavioral Analysis}

We used the difference in locomotor activity between days 2 and 3 (day 3-day 2) as the primary measure of drug sensitivity for the QTL and congenic analysis (Palmer et al, 2005). This measure takes into account differences in locomotor activity that are not specific to drug treatment. For the inhibitor study, we used day 3 activity as the measure of drug sensitivity because the vehicle for PF was only administered on day 3 and not day 2. For all behavioral studies, we first ran a repeated measures ANOVA (genotype and sex as factors; time as repeated measure) and determined that sex did not interact with genotype. Thus, the sexes were combined and repeated measures ANOVA followed by the indicated post-hoc test were employed to determine the main effects, interactions, and their source. 


\section{RESULTS}

\section{QTL}

We identified a QTL on chromosome 15 for day 3-day 2 activity following MA administration that peaked at $5 \mathrm{~min}$ and reached genome-wide significance $(\mathrm{LOD}=5.18$; $P<0.05$ significance threshold $=4.01)$. This $\mathrm{QTL}$ was not significant at 10 or $15 \mathrm{~min}$ (Figure 1a). The 1.5-LOD support interval ranged from 63 to $86 \mathrm{Mb}$, thus capturing Csnkle $(79.25-79.27 \mathrm{Mb})$. The $\mathrm{D} 2$ allele of the marker nearest the peak LOD score was associated with higher MA sensitivity in both the $\mathrm{F}_{2}\left(t_{274}=3.78 ; P<0.05\right)$ and $\mathrm{F}_{8}$ cross $\left(t_{282}=2.36\right.$; $P<0.05$; Figure $1 \mathrm{~b}$ and $\mathrm{c}$ ). We identified other genome-wide significant QTLs that are the subject of a separate investigation (Parker et al, 2011a, under review).

\section{Reciprocal Congenic Regions}

The congenic boundaries are illustrated in Figure $2 a$ and $b$ and documented in detail in Supplementary Table S1. The introgressed region of the B6.D2 ${ }^{\text {Csnkle }}$ line spanned $78-86.8 \mathrm{Mb}$ whereas for the D2.B6 ${ }^{\text {Csnkle }}$ line spanned $78.7-81.6 \mathrm{Mb}$. The latter region was estimated to be

a
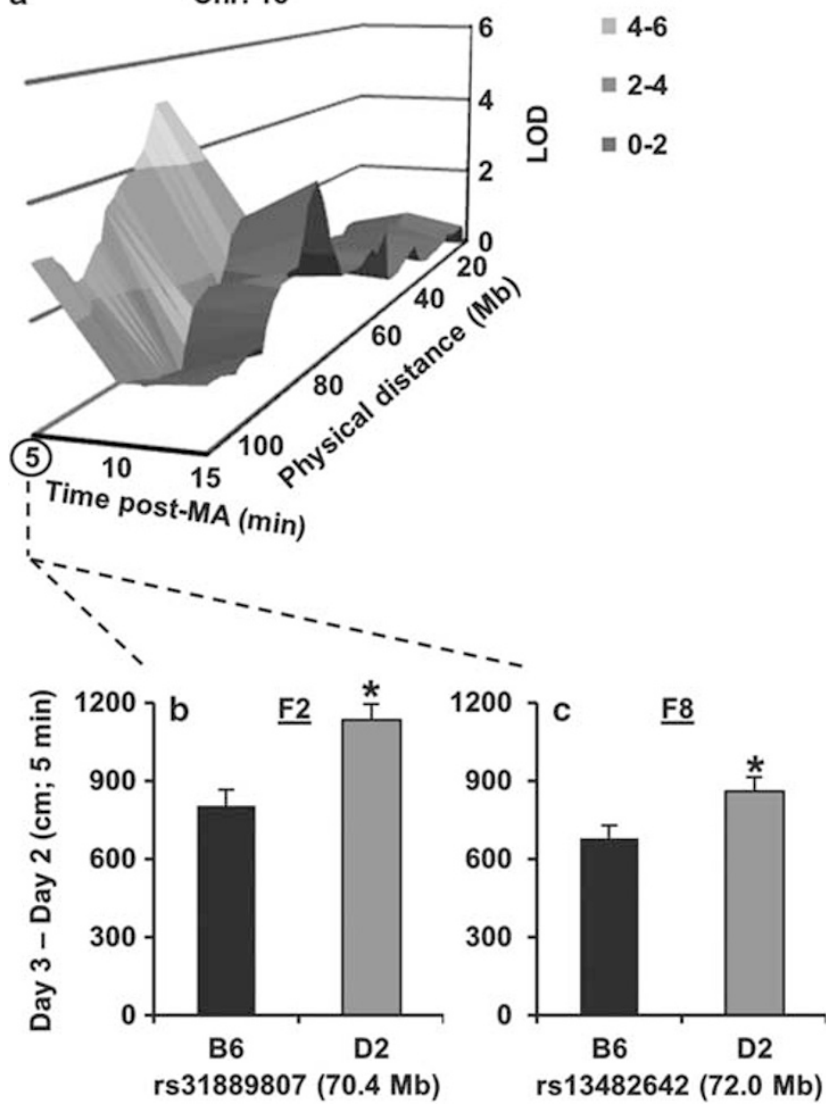

Figure I Chromosome 15 QTL for MA sensitivity in $B 6 \times D 2-F_{2}$ and $-F_{8}$ mice. (a) Three-dimensional plot of LOD score vs time after MA ( $2 \mathrm{mg} / \mathrm{kg}$, i.p.) vs physical position (Mb) of the SNP markers. The 1.5-LOD support interval was $63-86 \mathrm{Mb}$. (b, c) The D2 allele at the marker nearest the peak LOD was associated with an increase in MA sensitivity relative to the $\mathrm{B} 6$ allele in $\mathrm{F}_{2}$ and $\mathrm{F}_{8}$ mice. Data for each genotype are presented as the average \pm SEM. $* P<0.05$. $\sim 0.56 \mathrm{cM}$ (Cox et al, 2009). As expected, the results of the SNP array confirmed that each congenic line contained $<1 \%$ RH. Specifically, for B6.D2 ${ }^{\text {Csnk1e }}$, one individual did not harbor any RH whereas the second individual harbored $\mathrm{RH}$ at only 2 markers out of 882 . These SNPs were located on chromosome 11 (rs13480863; $9.19 \mathrm{Mb})$ and chromosome 13 (rs3663223; $23.18 \mathrm{Mb}$ ) and were confirmed via PCR and DNA sequencing of the region harboring the SNP. Neither of these $\mathrm{RH}$ loci resided in the two individuals tested from the D2.B6 ${ }^{\text {Csnkle }}$ line.

With respect to $\mathrm{D} 2 . \mathrm{B} 6^{\text {Csnk1e }}$ mice, one individual did not harbor any $\mathrm{RH}$, whereas the second individual harbored $\mathrm{RH}$ at 6 out of 882 markers (confirmed via PCR and DNA sequencing). In sum, the SNP array results indicate that RH in the congenic lines was very limited and was $<1 \%$. There was no pattern of $\mathrm{RH}$ within a line and $\mathrm{RH}$ resided in different loci between lines. As such, it is highly unlikely that $\mathrm{RH}$ was responsible for the predicted reciprocal effect on MA-induced locomotor activity. The most parsimonious explanation is that the region on chromosome 15 that mediates the QTL is the common denominator responsible for the expected change in phenotype across the congenic lines.

\section{MA sensitivity in B6.D2 ${ }^{\text {Csnk1e }}$ and D2.B6 ${ }^{\text {Csnk1e }}$ Reciprocal Congenic Mice}

In examining the response to $\mathrm{MA}$ in $\mathrm{B} 6 . \mathrm{D} 2{ }^{\text {Csnkle }}$ mice, there was a main effect of genotype $\left(\mathrm{F}_{1,64}=5.59 ; P<0.05\right)$ and time $\left(\mathrm{F}_{2,128}=75.15 ; P<0.05\right)$. B6.D2 ${ }^{\text {Csnk1e }}$ mice showed significantly greater MA-induced locomotor activity than B6.B6 ${ }^{\text {Csnkle }}$ mice at $5 \mathrm{~min}\left(t_{64}=3.94 ; P<0.05\right.$; Figure $\left.2 \mathrm{c}\right)$ but not at 10 or $15 \mathrm{~min}(P>0.05)$. D2.B6 ${ }^{\text {Csnkle }}$ mice demonstrated significantly less MA-induced locomotor activity than D2.D2 ${ }^{\text {Csnk1e }}$ mice at $5 \mathrm{~min} \quad\left(t_{88}=2.32 ; \quad P<0.05\right.$; Figure $2 \mathrm{~d}$ ) but not at 10 or $15 \mathrm{~min}(P>0.05)$. In sum, B6.D2 ${ }^{\text {Csnkle }}$ and D2.B6 ${ }^{\text {Csnkle }}$ mice exhibit the hypothesized reciprocal, time-dependent changes in MA sensitivity based on our previous observations (Palmer et al, 2005) and the QTL mapping results shown in Figure 1.

\section{Saline Control Experiment in B6.D2 ${ }^{\text {Csnkle }}$ and D2.B6 ${ }^{\text {Csnk1e }}$ Reciprocal Congenic Mice}

We performed a control experiment to ensure that the effect of the congenic region on MA-induced locomotor activity was specific to drug treatment and not explained by differences in drug-free activity between days 2 and 3 . Because we wanted to know how confidently we could interpret any negative results, we first conducted a power analysis to determine the required sample size for detecting an effect of genotype on locomotor activity. Based on the means and standard deviations of the two genotypes, we calculated the effect size $r$. We then converted these values to Cohen's $d$ and determined the sample size required to detect a significant difference of the two groups using G-Power 3.1 (http://www.psycho.uni-duesseldorf.de/aap/ projects/gpower/). The estimated effect size for the difference in MA-induced locomotor activity in B6.D2 ${ }^{\text {Csnkle mice }}$ is $r=0.44$. Thus, $N=14$ per genotype is required to detect this difference with $\alpha=0.05$ and $80 \%$ power. The estimated effect size for the difference in MA-induced locomotor 


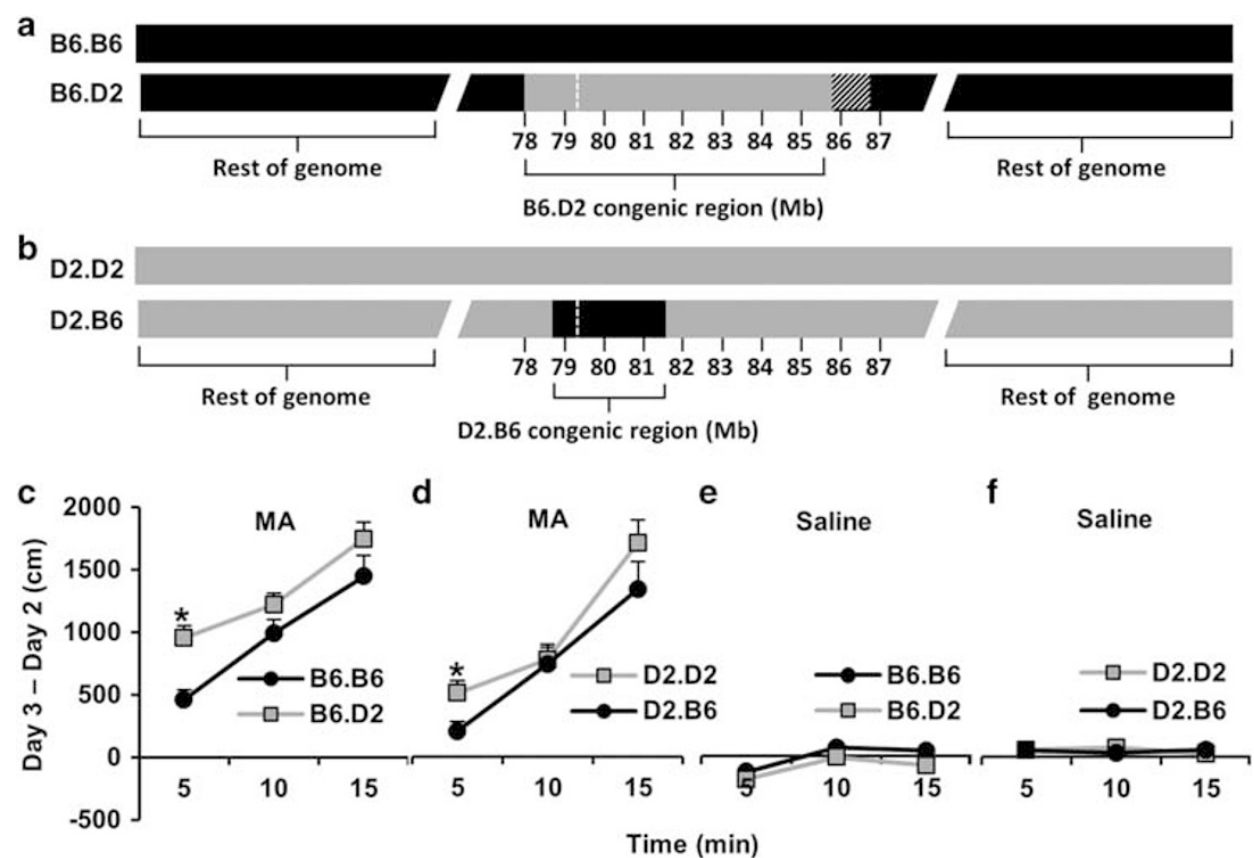

Figure 2 B6.D2 ${ }^{\text {Csnkle }}$ and D2.B6 ${ }^{\text {Csnkle }}$ reciprocal congenic regions and MA sensitivity. (a) The B6.D2 ${ }^{\text {Csnkle }}$ congenic line contained an introgressed region on chromosome 15 (gray) spanning 78-86.8 Mb. (b) The D2.B6 ${ }^{\text {Cnnkle }}$ congenic line contained a smaller introgressed region (black) spanning 78.7-8I.6 Mb (see Supplementary Table SI for additional details). 'Rest of genome' is $>99 \%$ homozygous for the respective background strain (black for B6, gray for D2) at genomic loci outside of the congenic regions. The diagonally striped region was not genotyped. The physical position of Csnk le is $79.25 \mathrm{Mb}$ (Dotted, white vertical line). (c, d) Day 3-day 2 activity is shown for B6.D2 ${ }^{\text {Csnkle }}$ mice $(N=32)$ vs their B6.B6 wild-type littermates $(N=34)$ and for D2.B6 ${ }^{\text {csnkle }}$ mice $(N=39)$ vs their D2.D2 ${ }^{\text {Csnkle }}$ wild-type littermates $(N=5 \mathrm{I})$ in response to MA (2 mg/kg, i.p.) on day 3. (e, f) Day 3-day 2 activity is shown for B6.D2 ${ }^{\text {Csnkle }}$ $(N=23)$ vs their B6.B6 ${ }^{\text {cnnkle }}$ wild-type littermates $(N=15)$ and for D2.B6 ${ }^{\text {Cnnkle }}(N=40)$ vs their D2.D2 $2^{\text {csnkle }}$ wild-type littermates $(N=40)$ in response to saline (i.p.) on day 3. Data for each genotype are presented as the average \pm SEM for each 5 min bin. $* P<0.05$.

activity in D2.B6 ${ }^{\text {Csnkle }}$ mice is $r=0.25$. Thus, $N=49$ per genotype is required to detect this difference.

Based on the power analysis, a separate cohort of congenic mice and their wild-type littermates received saline on day 3 instead of MA. In B6.D2 ${ }^{\text {Csnkle }}$ mice $(N=23)$ $v s \mathrm{~B} 6 . \mathrm{B6}^{\text {Csnkle }}$ mice $(N=15)$, there was no effect of genotype $(P>0.05)$. We confirmed this negative result by examining the first $5 \mathrm{~min}(P>0.05$; Figure 2e). With regard to D2.B6 ${ }^{\text {Csnkle }}$ mice $(N=40)$ vs D2.D2 ${ }^{\text {Csnkle }}$ mice $(N=40)$, there was no effect of genotype or an interaction with time; this negative result was also confirmed by examining the first $5 \mathrm{~min}(P>0.05$; Figure 2f). Thus, the congenic phenotype is specific to MA treatment and cannot be explained by drug-free differences in locomotor activity between days 2 and 3 .

\section{Fentanyl Sensitivity in B6.D2 ${ }^{\text {Csnkle }}$ Mice}

It is well documented that the D2 inbred strain is resistant to the locomotor stimulant effects of opioid agonists, including morphine (Belknap et al, 1989, 1998; Orsini et al, 2005; Fadda et al, 2005; Cunningham et al, 1992; Gwynn and Domino, 1984; Hynes and Berkowitz, 1982; Collins and Whitney, 1978; Brase et al, 1977), heroin (Bailey et al, 2010; Castellano et al, 1976), and methadone (Middaugh and Zemp, 1976). We confirmed this lack of sensitivity to fentanyl-induced locomotor activity in D2 mice, and thus only examined fentanyl sensitivity in B6.D2 ${ }^{\text {Csnk1e }}$ mice and their B6.B6 ${ }^{\text {Csnkle }}$ wild-type littermates. As predicted based on the MA results, $\mathrm{B} 6 . \mathrm{D} 2{ }^{\text {Csnkle }}$ mice

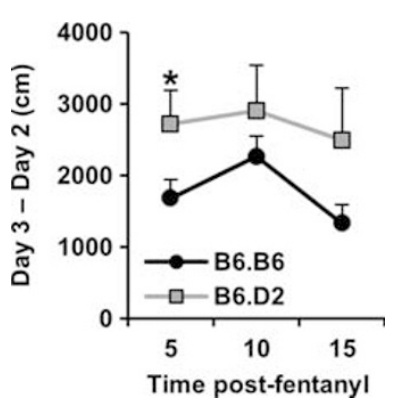

Figure 3 Fentanyl sensitivity in B6.D2 ${ }^{\text {Csnkle }}$ mice. Day 3-day 2 activity is shown for B6.D2 ${ }^{\text {Cnnkle }}$ mice $(N=11)$ vs their B6.B6 ${ }^{\text {Csnkle }}$ wild-type littermates $(N=16)$ in response to fentanyl $(0.2 \mathrm{mg} / \mathrm{kg}$, i.p.) on day 3. Data for each genotype are presented as the average \pm SEM for each $5 \mathrm{~min}$ bin. $* P<0.05$.

showed significantly greater fentanyl-induced locomotor activity than B6.B6 ${ }^{\text {snkie }}$ mice at 5 min $\left(t_{25}=2.09 ; P<0.05\right.$; Figure 3$)$ but not at 10 or $15 \mathrm{~min}(P>0.05)$.

\section{MA Sensitivity in Csnkle Knockout Mice}

For day 1, there was no effect of genotype and no genotype $\times$ time interaction $(P>0.05$; data not shown $)$. For day 2 , there was an effect of genotype $\left(\mathrm{F}_{1,52}=6.02\right.$; $P<0.05)$. Csnkle knockout mice showed greater activity in response to a saline injection than Csnkle wild-type mice at $10,15,20$, and $25 \mathrm{~min}\left(\mathrm{t}_{52}=3.12,2.34,2.67\right.$, and 2.02; $P<0.05$; Figure $4 a$ ). On day 3 , in response to MA, there was 


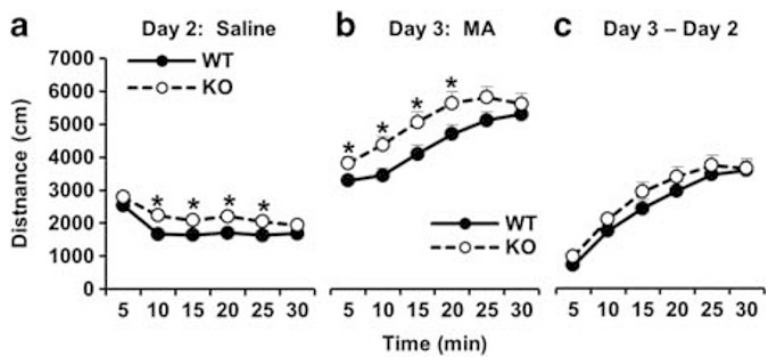

Figure 4 MA sensitivity in Csnk le knockout mice. (a) Locomotor activity on day 2 in response to saline (i.p.) in Csnkle knockout $(K O)$ mice $(N=28)$ vs Csnk le wild-type (WT) mice $(N=26)$. (b) Locomotor activity on day 3 in response to MA (2 mg/ $/ \mathrm{kg}$, i.p.). (c) Day 3-day 2 activity. Data for each genotype are presented as the average \pm SEM for each 5 min bin. $* P<0.05$.

an effect of genotype $\left(\mathrm{F}_{1,52}=4.13 ; P<0.05\right)$ and an interaction with time $\left(\mathrm{F}_{5,260}=2.69 ; P<0.05\right)$. Csnkle knockout mice showed greater MA-induced locomotor activity at $5,10,15$, and $20 \mathrm{~min}\left(t_{52}=2.19,2.70,2.29\right.$, and 2.07; $P<0.05$; Figure $4 \mathrm{~b})$. For day 3 -day 2 , there was no effect of genotype or interaction with time $(P>0.05$; Figure $4 \mathrm{c})$. Because the age range of mice used in this experiment was wide (8-21 weeks), we used a median split and divided the mice into a younger group and an older group and added 'age group' as an additional factor to the repeated measures ANOVA. The effect of genotype remained significant $(P<0.05)$, there was no effect of age group $(P>0.05)$, and there was no genotype $\times$ age group interaction $(P>0.05)$ for both days 2 and 3 (data not shown).

\section{Effect of PF-4800567 on MA and Fentanyl Sensitivity} in B6.B6 ${ }^{\text {Csnk1e }}$ and B6.D2 ${ }^{\text {Csnk1e }}$ Mice

In examining the effect of $\mathrm{PF}$ on MA sensitivity in B6.B6 ${ }^{\text {Csnkle }}$ mice, there was no effect of treatment $(P>0.05$; Figure $5 \mathrm{a})$; however, in B6.D2 $2^{\text {Csnkle }}$ mice, there was an effect of treatment $\left(\mathrm{F}_{1,35}=4.34 ; P<0.05\right)$ whereby mice receiving $P F$ showed significantly greater MA-induced locomotor activity than mice receiving vehicle over $30 \mathrm{~min}$ (Figure 5b). The effect of PF on fentanyl-induced locomotor stimulation was more robust and was observed in both genotypes. In $\mathrm{B} 6 . \mathrm{B}^{\mathrm{Csnk} 1 e}$ mice, there was an effect of treatment $\left(\mathrm{F}_{1,33}=9.07 ; \quad P<0.05\right)$ and an interaction with time $\left(\mathrm{F}_{5,165}=2.63 ; P<0.05\right)$ that was explained by PF-treated mice exhibiting greater fentanyl-induced locomotor activity than vehicle-treated mice at $5,15,20,25$, and $30 \mathrm{~min}\left(t_{33}=2.23,3.07,3.17,2.83\right.$, and $2.59 ; P<0.05$; Figure 5c). In B6.D2 ${ }^{\text {Csnk1e }}$ mice, there was a main effect of treatment $\left(\mathrm{F}_{1,28}=6.16 ; P<0.05\right)$ and an interaction with time $\left(\mathrm{F}_{5,140}=3.45 ; P<0.05\right)$ that was explained by PFtreated mice showing significantly greater fentanyl-induced locomotor activity than vehicle-treated mice at $15,20,25$, and $30 \mathrm{~min}\left(t_{28}=2.44,3.05,2.46\right.$, and $2.83 ; P<0.05$; Figure 5d). In this study, we did not observe an effect of genotype during the first $5 \mathrm{~min}$ and B6.D2 ${ }^{\text {Csnkle }}$ mice tended to show less fentanyl activity. We attribute these observations to environmental differences (either in the home cage or during testing) because the offspring came from homozygote breeders and because the genotypes could not always be tested on the same day. Importantly, it does a

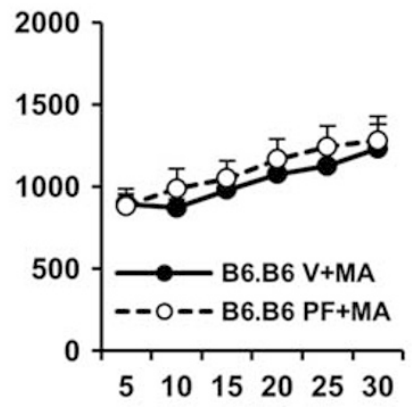

b
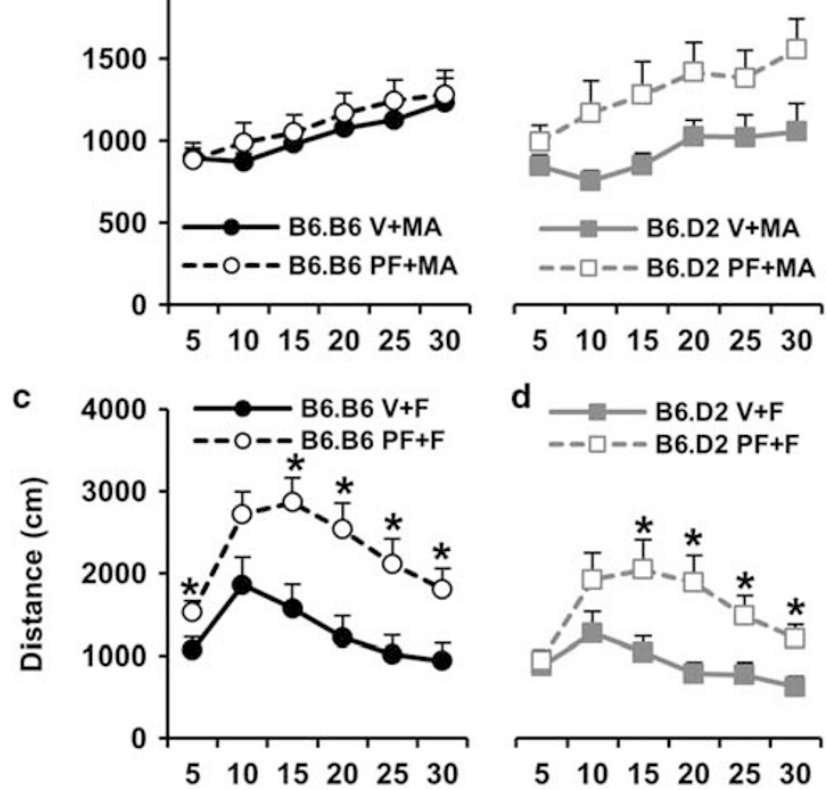

d

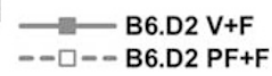

e

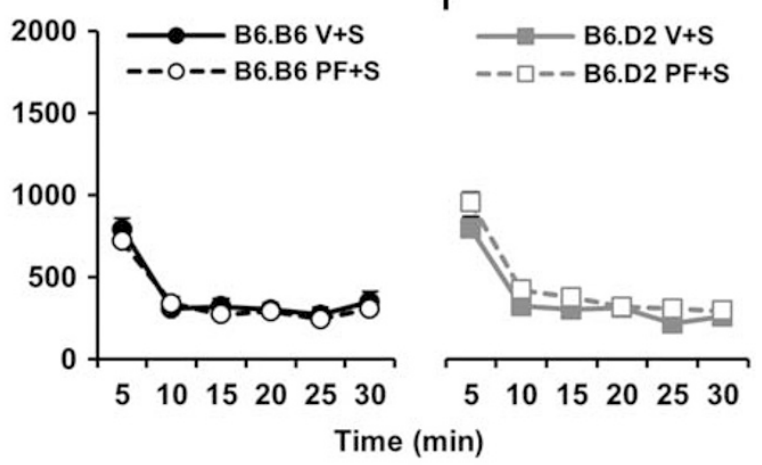

Figure 5 Effect of the Csnkle inhibitor PF-4800567 on MA and fentanyl sensitivity in B6.B6 ${ }^{\text {Snkle }}$ and B6.D2 ${ }^{\text {Cnnkle }}$ mice. (a, b) Effect of PF-4800567 (PF; $40 \mathrm{mg} / \mathrm{kg}$, i.p.) on MA-induced locomotor activity in B6.B6 $6^{\text {Csnkle }}$ mice $\left(N=18\right.$ vehicle $(V)$-treated, $N=19$ PF-treated mice) and B6.D2 ${ }^{\text {Cnnkle }}$ mice ( $N=18 \mathrm{~V}$-treated, $N=20$ PF-treated mice). (c, d) Effect of PF on fentanyl

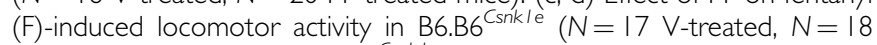

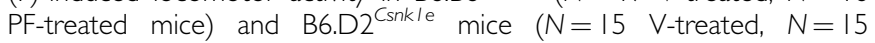
PF-treated mice). (e, f) Effect of PF on saline (S)-induced locomotor activity in $\mathrm{B} . \mathrm{B6}^{\mathrm{C} \text { snkle }}(\mathrm{N}=18 \mathrm{~V}$-treated, $N=17 \mathrm{PF}$-treated mice) and B6.D2 ${ }^{\text {csnkle }}$ mice ( $N=17 \mathrm{~V}$-treated, $N=16$ PF-treated mice). Data for each genotype/treatment are presented as the average \pm SEM for each 5 min bin. $* P<0.05$.

not affect the overall conclusion that pharmacological inhibition of Csnkle increased sensitivity to both MA and fentanyl.

Saline Control Experiment of PF-4800567 on Locomotor Activity in B6.B6 ${ }^{\text {snk1e }}$ and B6.D2 ${ }^{\text {Csnk1e }}$ Mice

In order to rule out the possibility that the enhancement of fentanyl-induced locomotor activity was mediated by a nonspecific increase in locomotor activity by PF, we ran a separate control experiment where PF was administered with saline $(\mathrm{PF}+\mathrm{S})$ and compared with a second group receiving vehicle plus saline $(\mathrm{V}+\mathrm{S})$. We first conducted a power analysis to determine the required sample size for 
detecting an effect of the inhibitor on fentanyl-induced locomotor activity ( $\alpha=0.05 ; 80 \%$ power). The effect size in $\mathrm{B} 6 . \mathrm{B} 6^{\text {Csnkle }}$ mice is $r=0.45$ and the required sample size is $N=13$. The effect size in B6.D2 ${ }^{\text {Csnk1e }}$ mice is $r=0.41$ and the required sample size is $N=16$. Following PF treatment alone, there was no effect of treatment or interaction with time in B6.B6 mice (Figure 5e; $N=18$ vehicle-treated, $N=17 \quad$ PF-treated mice; $P>0.05)$ or in B6.D2 mice (Figure 5f; $N=17$ vehicle-treated, $N=16 \mathrm{PF}$-treated mice; $P>0.05)$, demonstrating that the enhancement of psychostimulant and opioid sensitivity by PF depends on their locomotor stimulant properties.

\section{DISCUSSION}

Using QTL and congenic analysis, we localized a small region on chromosome 15 flanking Csnkle that modulates MA sensitivity (78.7-81.6 Mb; Figures 1 and 2). As predicted from our previous study using selected lines (Palmer et al, 2005), the D2 allele increased sensitivity to MA (Figures $1 \mathrm{~b}$ and $\mathrm{c}$ and $2 \mathrm{c}$ and $\mathrm{d}$ ). The Csnkle locus regulated MA sensitivity in a time-dependent manner (Figure 1a) and, remarkably, the results of reciprocal congenic mice showed identical time dependence (Figure $2 \mathrm{c}$ and $\mathrm{d}$ ). Thus, several independent lines of genetic evidence suggest that variation at the Csnkle locus can regulate the locomotor response to $\mathrm{MA}$, even when placed on different genetic backgrounds $\left(\mathrm{F}_{2} / \mathrm{F}_{8}, \mathrm{~B} 6\right.$, and $\left.\mathrm{D} 2\right)$. Interestingly, we recently replicated the association of the CSNK1E SNP rs135745 with amphetamine-induced subjective euphoria (Veenstra-VanderWeele et al 2006) in healthy human volunteers in a new cohort of 282 subjects (Amy et al, unpublished data).

The Csnk1e locus also affected opioid sensitivity (Figure 3) which, along with a previous association between a SNP in CSNK1E and heroin dependence (Levran et al, 2008), further implicates Csnkle as a genetic regulator of sensitivity to drugs of abuse. Of particular note, a nearly identical genetic locus that we have identified $(77-83 \mathrm{Mb} v s 79-82 \mathrm{Mb}$ in the present study) also regulates alcohol consumption in mice (Boyle and Gill, 2008). The convergence of a QTL on this region for the response to psychostimulants, opioids, and ethanol implicates gene(s) acting via dopaminergic mechanisms (Di Chiara and Imperato, 1988). Last, genetic (Figure 4b) and pharmacological (Figure 5b) inhibition of Csnkle increased MA sensitivity and opioid sensitivity (Figure $5 \mathrm{c}$ and $\mathrm{d}$ ). Together, these results suggest that genetic variation in Csnkle modulates sensitivity to drugs of abuse and define a specific role for Csnkle in negatively regulating sensitivity to both psychostimulants and opioids.

The effects of both the B6.D2 ${ }^{\text {Csnkle }}$ and D2.B6 $6^{\text {Csnkle }}$ intervals were specific to the locomotor stimulant properties of MA and fentanyl because there was no effect on locomotor activity following saline treatment (Figure 2e and f). Similarly, the selective Csnk1e inhibitor PF-4800567 increased both MA and fentanyl sensitivity (Figure 5b-d) while having no effect on locomotor activity following saline treatment (Figure 5e and f). PF-4800567 shows $>20$-fold selectivity for Csnk1e over Csnk1d and exhibits markedly reduced efficacy at inhibiting off-target proteins relative to PF-670462. Nevertheless, both PF-4800567 and PF-670462 can significantly inhibit epidermal growth factor receptor (EGFR) at micromolar concentrations (Walton et al, 2009). We are unaware of any study examining the acute effect of selective inhibition of EGFR on psychostimulant- or opioidinduced locomotor activity. Emodin, a nonselective compound that inhibits EGFR signaling (and ERK1/2 signaling among others) caused a significant reduction in the locomotor response to MA (Mizuno et al, 2008, 2010). However, these results are not consistent with the effect that PF-4800567 had on MA- and fentanyl-induced locomotor activity, which was an increase and not a decrease in locomotor activity.

Csnkle knockout mice exhibited a significant increase in locomotor activity in both the absence and presence of MA (Figure 4a and b). Interestingly, this phenotype is very similar to what was observed following overexpression of Csnkld in the forebrain: baseline hyperactivity that persisted following the administration of amphetamine (Zhou et al, 2010). Together, the results of these reverse genetic manipulations suggest that Csnkle has an inhibitory role and Csnkld has a facilitating role in regulating locomotor activity in the open field. A limitation of our results is that the knockout mice were only backcrossed to C57BL/6N for six generations (Meng et al, 2008) and are not congenic. Thus, the effect of the mutation on locomotor activity could be an artifact caused by the mixed background. However, the first cohort of mice we tested included littermate controls, which addresses this concern by randomizing all unfixed alleles. This cohort showed results very similar to those in Figure 3 (data not shown), suggesting that the $\mathrm{KO}$ allele and not the mixed genetic background caused the observed phenotypic differences.

Our results do not demonstrate that a polymorphism in Csnkle causes the QTL on chromosome 15. There are over 400 potentially functional polymorphisms in over 40 genes within the $79-82 \mathrm{Mb}$ congenic region (Figure $2 \mathrm{~b}$ and Supplementary Table S2). In principal, any of these polymorphisms could underlie the QTL. However, it is interesting to note that PF only enhanced MA sensitivity in B6.D2 ${ }^{\text {Csnkie }}$ mice and not B6.B6 ${ }^{\text {Csnkle }}$ mice (Figure $5 \mathrm{a}$ and b), consistent with the hypothesis that genetic variation in Csnkle could be responsible for the differential effect of Csnkle inhibition on MA-induced locomotor activity. This difference cannot be explained by insufficient dosing of $\mathrm{PF}$ because $\mathrm{B} 6 . \mathrm{B}^{\text {Csnkle }}$ mice responded to PF-induced enhancement of fentanyl-induced locomotor activity (Figure $5 \mathrm{c}$ ). Nor can it be explained by too high of a dose because PF did not affect MA sensitivity in B6.B6 ${ }^{\text {Csnkle }}$ mice using a lower dose either $(20 \mathrm{mg} / \mathrm{kg}$; data not shown). The result could be explained by genetic variation in Csnkle that affects its expression and/or function. Alternatively, we may have been underpowered to detect the PF-induced enhancement in $\mathrm{B} 6 . \mathrm{B6}^{\mathrm{Csnk1e}}$ mice (Figure 5a), given that PF had a more subtle effect on MA-induced locomotor activity in B6.D2 ${ }^{\text {Csnkle }}$ mice (Figure 5b) compared with the large enhancement observed in both genotypes on fentanylinduced locomotor activity (Figure $5 c$ and d). Because of the rapid onset of fentanyl-induced locomotor activity, the effect of PF may have been easier to observe in both genotypes.

In contrast to the results observed with PF-4800567, we previously found that the CK-1 inhibitor PF-670462 
decreased MA sensitivity (Bryant et al, 2009b; Li et al, 2011). PF-670462 was previously thought to be slightly more selective for Csnk1e over Csnk1d (Badura et al, 2007), but a recent study showed that PF-670462 was six-fold more selective for Csnk1d over Csnkle and that PF-4800567 was 20 -fold more selective for Csnk1e over Csnk1d (Walton et al, 2009). Because PF-4800567 increased MA and fentanyl sensitivity whereas PF-670462 decreased MA sensitivity, the combined results provide further evidence that Csnkle and Csnk1d exert opposing regulatory roles on the locomotor stimulant response to drugs of abuse.

Psychostimulants and opioids induce a locomotor stimulant response via dopamine release in the nucleus accumbens (Di Chiara and Imperato, 1988). This leads to the activation of DARPP-32 in part via CK-1 (Greengard, 2001) and we previously showed that coadministration of the Csnk1d-preferring compound PF-4076462 inhibited MA-induced DARPP-32 phosphorylation (Bryant et al, 2009b; Li et al, 2011). As such, how is it that two closely related isoforms might exert opposing effects on sensitivity to drugs of abuse? One possibility is that cell type-specific expression of the two isoforms mediates the results. Although the general distribution of expression of Csnk1e and Csnk1d in the brain is similar, specificity of Csnk1e and Csnk1d expression has been observed in cell types such as Purkinje cells and astroglia (Utz et al, 2010; Lohler et al, 2009). Furthermore, a recent study showed that loss of DARPP-32 in D1-expressing cells reduced baseline and cocaine-induced locomotor activity whereas loss of DARPP32 in D2-expressing cells increased baseline and cocaineinduced locomotor activity (Bateup et al, 2010). Thus, it is possible that Csnk1d is preferentially expressed in D1-containing cells and that Csnk1e is expressed in D2containing cells. Interestingly, in examining the transcriptional profile of D1- vs D2-expressing cells following acute cocaine treatment, a significant increase in expression of Csnk1d was observed specifically in D1 cells and not D2 cells (Heiman et al, 2008). A separate possibility is that Csnk1e and Csnk1d modulate signaling pathways other than DARPP-32 that are responsible for their differential effects on drugs of abuse.

One unanswered question is the nature of the polymorphism in Csnkle that we hypothesize to account for the observed QTL. There are several Csnkle SNPs between the B6 and D2 strains, some of which are located near the transcriptional start site (http://www.informatics.jax.org), and thus could affect expression. The latest DNA sequencing results of inbred mouse strains (Keane et al, 2011) indicate that there are 12 potentially functional Csnkle SNPs between B6 and D2 located within the $3^{\prime}$ UTR (Supplementary Table S2), any of which could influence mRNA stability. Additionally, cis-acting expression QTLs near Csnkle derived from $\mathrm{B} 6$ and $\mathrm{D} 2$ genotypes have been observed in several brain areas using multiple microarray platforms (http://www.genenetwork.org). We and others did not observe a difference in Csnkle expression in the striatum either via real-time quantitative PCR (data not shown) or via RNA sequencing (Bottomly et al, 2011). However, it is possible that a difference in Csnkle expression at other developmental time points, other brain areas, or in specific cell types mediates the observed association with behavior.
The present series of studies combine forward and reverse genetics with pharmacological methods to identify Csnkle as a negative genetic regulator of sensitivity to psychostimulants and opioids. Future studies will examine the brain areas, cell types, and signaling mechanisms by which we propose Csnk1e and Csnk1d to exert their dual regulatory roles in drug sensitivity. It will be important to examine the differential role that Csnk1e and Csnk1d might play in drug reward and reinforcement (Zhang et al, 2006) and the response to other abused substances such as alcohol.

\section{ACKNOWLEDGEMENTS}

This work was supported by R01DA021336 (AAP), R01MH079103 (AAP), K99DA029635 (CDB), F32DA026697 (CDB), T32DA007255 (CDB and CCP), and R01MH068013 (VJB). We thank Dr Joseph Takahashi and Dr Caroline H Ko for providing the Csnk1e knockout breeders and Dr Jake Lusis and Dr Richard Davis for providing B6.D2 congenic mice.

\section{DISCLOSURE}

$\mathrm{CDB}, \mathrm{CCP}, \mathrm{LZ}, \mathrm{CO}, \mathrm{ASL}, \mathrm{VJB}$, and AAP have nothing to disclose. RYC and TTW are employed by Pfizer. MHV receives financial support from Institut de Recherches Internationales Servier and DARPA/ARO. FWT receives grant research support from Merck, Takeda Pharmaceuticals, Astra-Zeneca, American Waterways Operators, March of Dimes, NHLBI, NIA, and the Department of Defense and is a consultant for Takeda Pharmaceuticals, Merck, Servier, Pinnacle Technology, Astra-Zeneca, SanofiAventis, Philips Respironics, and Ingram Barge Company.

\section{REFERENCES}

Badura L, Swanson T, Adamowicz W, Adams J, Cianfrogna J, Fisher $\mathrm{K}$ et al (2007). An inhibitor of casein kinase I epsilon induces phase delays in circadian rhythms under free-running and entrained conditions. J Pharmacol Exp Ther 322: 730-738.

Bailey A, Metaxas A, Al-Hasani R, Keyworth HL, Forster DM, Kitchen I (2010). Mouse strain differences in locomotor, sensitisation and rewarding effect of heroin; association with alterations in MOP-r activation and dopamine transporter binding. Eur J Neurosci 31: 742-753.

Bateup HS, Santini E, Shen W, Birnbaum S, Valjent E, Surmeier DJ et al (2010). Distinct subclasses of medium spiny neurons differentially regulate striatal motor behaviors. Proc Natl Acad Sci USA 107: 14845-14850.

Belknap JK, Noordewier B, Lame M (1989). Genetic dissociation of multiple morphine effects among C57BL/6J, DBA/2J and $\mathrm{C} 3 \mathrm{H} / \mathrm{HeJ}$ inbred mouse strains. Physiol Behav 46: 69-74.

Belknap JK, Riggan J, Cross S, Young ER, Gallaher EJ, Crabbe JC (1998). Genetic determinants of morphine activity and thermal responses in 15 inbred mouse strains. Pharmacol Biochem Behav 59: 353-360.

Borgkvist A, Fisone G (2007). Psychoactive drugs and regulation of the cAMP/PKA/DARPP-32 cascade in striatal medium spiny neurons. Neurosci Biobehav Rev 31: 79-88.

Borgkvist A, Usiello A, Greengard P, Fisone G (2007). Activation of the cAMP/PKA/DARPP-32 signaling pathway is required for morphine psychomotor stimulation but not for morphine reward. Neuropsychopharmacology 32: 1995-2003. 
Bottomly D, Walter NA, Hunter JE, Darakjian P, Kawane S, Buck KJ et al (2011). Evaluating gene expression in C57BL/6J and DBA/2J mouse striatum using RNA-Seq and microarrays. PLoS One 6: e17820.

Boyle AE, Gill KJ (2008). Confirmation of provisional quantitative trait loci for voluntary alcohol consumption: genetic analysis in chromosome substitution strains and F2 crosses derived from $\mathrm{A} / \mathrm{J}$ and $\mathrm{C} 57 \mathrm{BL} / 6 \mathrm{~J}$ progenitors. Pharmacogenet Genomics 18: 1071-1082.

Brase DA, Loh HH, Way EL (1977). Comparison of the effects of morphine on locomotor activity, analgesia and primary and protracted physical dependence in six mouse strains. J Pharmacol Exp Ther 201: 368-374.

Bryant CD, Chang HP, Zhang J, Wiltshire T, Tarantino LM, Palmer AA (2009a). A major QTL on chromosome 11 influences psychostimulant and opioid sensitivity in mice. Genes Brain Behav 8: 795-805.

Bryant CD, Graham ME, Distler MG, Munoz MB, Li D, Vezina P et al (2009b). A role for casein kinase 1 epsilon in the locomotor stimulant response to methamphetamine. Psychopharmacology 203: 703-711.

Bryant CD, Roberts KW, Culbertson CS, Le A, Evans CJ, Fanselow MS (2009c). Pavlovian conditioning of multiple opioid-like responses in mice. Drug Alcohol Depend 103: 74-83.

Castellano C, Filibeck L, Oliverio A (1976). Effects of heroin, alone or in combination with other drugs, on the locomotor activity in two inbred strains of mice. Psychopharmacology (Berl) 49: 29-31.

Cheng R, Abney M, Palmer AA, Skol AD (2011). QTLRel: an R package for genome-wide association studies in which relatedness is a concern. BMC Genet 12: 66 .

Cheng R, Lim JE, Samocha KE, Sokoloff G, Abney M, Skol AD et al (2010). Genome-wide association studies and the problem of relatedness among advanced intercross lines and other highly recombinant populations. Genetics 185: 1033-1044.

Cheong JK, Virshup DM (2010). Casein kinase 1: complexity in the family. Int J Biochem Cell Biol 43: 465-469.

Collins RL, Whitney G (1978). Genotype and test experience determine responsiveness to morphine. Psychopharmacology (Berl) 56: 57-60.

Cox A, Ackert-Bicknell CL, Dumont BL, Ding Y, Bell JT, Brockmann GA et al (2009). A new standard genetic map for the laboratory mouse. Genetics 182: 1335-1344.

Cunningham CL, Niehus DR, Malott DH, Prather LK (1992). Genetic differences in the rewarding and activating effects of morphine and ethanol. Psychopharmacology (Berl) 107: 385-393.

Di Chiara G, Imperato A (1988). Drugs abused by humans preferentially increase synaptic dopamine concentrations in the mesolimbic system of freely moving rats. Proc Natl Acad Sci USA 85: 5274-5278.

Dlugos AM, Hamidovic A, Hodgkinson C, Shen PH, Goldman D, Palmer AA et al (2011). OPRM1 gene variants modulate amphetamine-induced euphoria in humans. Genes Brain Behav 10: 199-209.

Fadda P, Scherma M, Fresu A, Collu M, Fratta W (2005). Dopamine and serotonin release in dorsal striatum and nucleus accumbens is differentially modulated by morphine in DBA/2J and C57BL/6J mice. Synapse 56: 29-38.

Falcon E, McClung CA (2008). A role for the circadian genes in drug addiction. Neuropharmacology 56(Suppl 1): 91-96.

Flagel SB, Clark JJ, Robinson TE, Mayo L, Czuj A, Willuhn I et al (2011). A selective role for dopamine in stimulus-reward learning. Nature 469: 53-57.

Gill KJ, Boyle AE (2008). Genetic influences on drug-induced psychomotor activation in mice. Genes Brain Behav 7: 859-868.

Greengard P (2001). The neurobiology of slow synaptic transmission. Science (New York, NY) 294: 1024-1030.

Gwynn GJ, Domino EF (1984). Genotype-dependent behavioral sensitivity to mu vs. kappa opiate agonists. I. Acute and chronic effects on mouse locomotor activity. J Pharmacol Exp Ther 231: 306-311.

Haertzen CA, Kocher TR, Miyasato K (1983). Reinforcements from the first drug experience can predict later drug habits and/or addiction: results with coffee, cigarettes, alcohol, barbiturates, minor and major tranquilizers, stimulants, marijuana, hallucinogens, heroin, opiates and cocaine. Drug Alcohol Depend 11: $147-165$.

Hamidovic A, Dlugos A, Palmer AA, de Wit H (2010). Polymorphisms in dopamine transporter (SLC6A3) are associated with stimulant effects of D-amphetamine: an exploratory pharmacogenetic study using healthy volunteers. Behav Genet 40: 255-261.

Hamidovic A, Dlugos A, Skol A, Palmer AA, de Wit H (2009). Evaluation of genetic variability in the dopamine receptor D2 in relation to behavioral inhibition and impulsivity/sensation seeking: an exploratory study with d-amphetamine in healthy participants. Exp Clin Psychopharmacol 17: 374-383.

Heiman M, Schaefer A, Gong S, Peterson JD, Day M, Ramsey KE et al (2008). A translational profiling approach for the molecular characterization of CNS cell types. Cell 135: 738-748.

Ho MK, Goldman D, Heinz A, Kaprio J, Kreek MJ, Li MD et al (2010). Breaking barriers in the genomics and pharmacogenetics of drug addiction. Clin Pharmacol Ther 88: 779-791.

Hynes MD, Berkowitz BA (1982). Lack of an opiate response to nitrous oxide in mice resistant to the activity-stimulating effects of morphine. J Pharmacol Exp Ther 220: 499-503.

Iakoubova OA, Olsson CL, Dains KM, Ross DA, Andalibi A, Lau K et al (2001). Genome-tagged mice (GTM): two sets of genomewide congenic strains. Genomics 74: 89-104.

Keane TM, Goodstadt L, Danecek P, White MA, Wong K, Yalcin B et al (2011). Mouse genomic variation and its effect on phenotypes and gene regulation. Nature 477: 289-294.

Levran O, Londono D, O'Hara K, Nielsen DA, Peles E, Rotrosen J et al (2008). Genetic susceptibility to heroin addiction; a candidate-gene association study. Genes Brain Behav 7: 720-729.

Li D, Herrera S, Bubula N, Nikitina E, Palmer AA, Hanck DA et al (2011). Casein kinase 1 enables nucleus accumbens amphetamine induced locomotion by regulating AMPA receptor phosphorylation. J Neurochem 118: 237-247.

Li X, Jope RS (2010). Is glycogen synthase kinase-3 a central modulator in mood regulation? Neuropsychopharmacology 35: 2143-2154.

Lohler J, Hirner H, Schmidt B, Kramer K, Fischer D, Thal DR et al (2009). Immunohistochemical characterisation of cell-type specific expression of CK1delta in various tissues of young adult BALB/c mice. PLoS One 4: e4174.

Lott DC, Kim SJ, Cook EH, de Wit H (2006). Serotonin transporter genotype and acute subjective response to amphetamine. Am J Addict 15: 327-335.

Lott DC, Kim SJ, Cook Jr EH, de Wit H (2005). Dopamine transporter gene associated with diminished subjective response to amphetamine. Neuropsychopharmacology 30: 602-609.

Meng QJ, Logunova L, Maywood ES, Gallego M, Lebiecki J, Brown TM et al (2008). Setting clock speed in mammals: the CK1 epsilon tau mutation in mice accelerates circadian pacemakers by selectively destabilizing PERIOD proteins. Neuron 58: 78-88.

Meng QJ, Maywood ES, Bechtold DA, Lu WQ, Li J, Gibbs JE et al (2010). Entrainment of disrupted circadian behavior through inhibition of casein kinase 1 (CK1) enzymes. Proc Natl Acad Sci USA 107: 15240-15245.

Middaugh LD, Zemp JW (1976). Effects of methadone on activity and on brain monoamines in two strains of mice. Pharmacol Biochem Behav 5: 367-370.

Mizuno M, Kawamura H, Ishizuka Y, Sotoyama H, Nawa H (2010). The anthraquinone derivative emodin attenuates methamphetamine-induced hyperlocomotion and startle response in rats. Pharmacol Biochem Behav 97: 392-398. 
Mizuno M, Kawamura H, Takei N, Nawa H (2008). The anthraquinone derivative Emodin ameliorates neurobehavioral deficits of a rodent model for schizophrenia. J Neural Transm 115: 521-530.

Oliverio A, Castellano C, Eleftheriou BE (1975). Morphine sensitivity and tolerance: a genetic investigation in the mouse. Psychopharmacologia 42: 219-224.

Orsini C, Bonito-Oliva A, Conversi D, Cabib S (2005). Susceptibility to conditioned place preference induced by addictive drugs in mice of the $\mathrm{C} 57 \mathrm{BL} / 6$ and $\mathrm{DBA} / 2$ inbred strains. Psychopharmacology (Berl) 181: 327-336.

Palmer AA, Verbitsky M, Suresh R, Kamens HM, Reed CL, Li N et al (2005). Gene expression differences in mice divergently selected for methamphetamine sensitivity. Mamm Genome 16: 291-305.

Parker CC, Cheng R, Sokoloff G, Lim JE, Skol AD, Abney M et al (2011). Fine-mapping alleles for body weight in LG/J $\times \mathrm{SM} / \mathrm{J} \mathrm{F}(2)$ and F (34) advanced intercross lines. Mamm Genome 22: 563-571.

Parker CC, Cheng R, Sokoloff G, Palmer AA (2011a). Genomewide association for methamphetamine sensitivity in an advanced intercross line. Genes Brain Behav; e-pub ahead of print 27 October 2011; doi:10.1111/j.1601-183X.2011.00747.x.

Petkov PM, Cassell MA, Sargent EE, Donnelly CJ, Robinson P, Crew V et al (2004). Development of a SNP genotyping panel for genetic monitoring of the laboratory mouse. Genomics 83: 902-911.

Philip VM, Duvvuru S, Gomero B, Ansah TA, Blaha CD, Cook MN et al (2010). High-throughput behavioral phenotyping in the expanded panel of BXD recombinant inbred strains. Genes Brain Behav 9: 129-159.

Phillips TJ, Kamens HM, Wheeler JM (2008). Behavioral genetic contributions to the study of addiction-related amphetamine effects. Neurosci Biobehav Rev 32: 707-759.
Schuckit MA (2009). An overview of genetic influences in alcoholism. J Subst Abuse Treat 36: S5-14.

Singh PP, Junnarkar AY, Seshagirirao C, Kaushal R, Naidu MU, Varma RK et al (1982). A pharmacological study of propane-1,2diol. Arzneimittelforschung 32: 1443-1446.

Utz AC, Hirner H, Blatz A, Hillenbrand A, Schmidt B, Deppert W et al (2010). Analysis of cell type-specific expression of CK1 epsilon in various tissues of young adult BALB/c Mice and in mammary tumors of SV40 T-Ag-transgenic mice. J Histochem Cytochem 58: 1-15.

Veenstra-VanderWeele J, Qaadir A, Palmer AA, Cook Jr EH, de Wit $\mathrm{H}$ (2006). Association between the casein kinase 1 epsilon gene region and subjective response to D-amphetamine. Neuropsychopharmacology 31: 1056-1063.

Walton KM, Fisher K, Rubitski D, Marconi M, Meng QJ, Sladek M et al (2009). Selective inhibition of casein kinase 1 epsilon minimally alters circadian clock period. J Pharmacol Exp Ther 330: $430-439$.

Wise RA, Bozarth MA (1987). A psychomotor stimulant theory of addiction. Psychol Rev 94: 469-492.

Zhang Y, Svenningsson P, Picetti R, Schlussman SD, Nairn AC, Ho A et al (2006). Cocaine self-administration in mice is inversely related to phosphorylation at Thr34 (protein kinase A site) and Ser130 (kinase CK1 site) of DARPP-32. J Neurosci 26: 2645-2651.

Zhou M, Rebholz H, Brocia C, Warner-Schmidt JL, Fienberg AA, Nairn AC et al (2010). Forebrain overexpression of CK1delta leads to down-regulation of dopamine receptors and altered locomotor activity reminiscent of ADHD. Proc Natl Acad Sci USA 107: 4401-4406.

Supplementary Information accompanies the paper on the Neuropsychopharmacology website (http://www.nature.com/npp) 